\title{
THE INFLUENCE OF LAND-USE LAND-COVER CHANGES ON URBAN BIRD COMMUNITIES
}

\author{
A.A.Ali ${ }^{1}$, N.H. Idris ${ }^{1}$, M.H.I.Ishak ${ }^{2}$ \\ ${ }^{1}$ Department of Geoinformation, Faculty of Built Environment and Survey, Universiti Teknologi Malaysia, UTM Skudai, 81310, \\ Johor Bahru, Malaysia \\ ${ }^{2}$ School of Electrical Engineering, Faculty Engineering, Universiti Teknologi Malaysia, UTM Skudai, 81310, Johor Bahru, Malaysia \\ ainaamirahali@gmail.com; hawani@utm.my, hafis@utm.my
}

KEY WORDS: Land Use Land Cover Changes, Urban Bird, eBird Crowd sourcing Data, Birds, Urban

\begin{abstract}
:
City development changes the landscape and has been claimed to pose threat to the survival of birds that heavily relies on healthy forest ecosystem. As such, this study assessed the effect of land-use land-cover (LULC) changes due to sub-urbanisation on birds' community using geostatistical method. In this study, geostatistical analyses, namely Kernel Density and Ordinary Least Square (OLS), were executed to identify the dominant factors that affected the bird's community in the Johor Bahru region. The birding data were obtained from eBird, an online crowd source database of bird distribution. The distribution of bird community was analysed by using Kernel density for years 2016 and 2018. This study found that the hotspot locations of the birds were in Danga Bay and Kempas Denai for year 2016, whereas Kampung Pok, Bukit Chagar, Taman Sentosa and Kampung Dato Sulaiman Menteri for year 2018. Certain urban bird species increased from year 2016 to 2018. The OLS regression was applied to analyse the relationship between birds' occurrence and LULC features within the study area. The global regression model indicated that distance to forest and distance to recreational and open space were positively associated with the number of bird occurrence. On the contrary, distance to road was negatively associated with the number of bird occurrence. The OLS model for year 2016 between birds' occurrence and distance to road, distance to forest, as well as distance to recreational and open space, demonstrated an adjusted R2 value of 0.32 . In year 2018, the correlation between birds' occurrence and distance to road, as well as distance to recreational and open space, demonstrated an adjusted R2 value of 0.11. As a conclusion, urbanisation seems to affect the birds' communities as it increases the number of urban birds spotted in Johor Bahru, which is attributed to the increasing recreational and open space areas in Johor Bahru. The study outcomes can be applied to comprehend the relationship between birds' community and LULC changes, as a result of urbanisation.
\end{abstract}

\section{INTRODUCTION}

Malaysia is a country rich in resources with a variety of tropical biodiversity within the East Asia region. The past three decades have demonstrated urban development as one of the significant plans of national social and economic development. In fact, there is a possibility that human population will be isolated from nature, particularly due to over $50 \%$ of the world's human populace residing in urban regions (Wang et al., 2019).

Birds are the most noticeable groups of animals that are avail in natural habitats from virgin jungles to urban backyard (or nurseries) (Duncan et al., 2014). Birds are important in monitoring healthy and functional ecosystem. According to Vrschmalhofer (2018), birds' role in ecological cycle as preys and predators and as source of food for scavengers are undeniable; birds acts as local and global nutrients dispersal agents. As they can fly over great distance and passing by different habitats, their digestive waste is useful adding in soil nutrients for plants growth (Amanullah et al., 2010). Whereas, as agents in pollination and seed dispersal processes, they help in the regeneration of plant species (Kitamura, 2015). Bird also have important role in human society as certain species are the source of local consumption such as quail for its meat and swiftlet for its edible nests (Chua and Zukefli, 2016). Birds also have been the subject of arts and in recreation activity. Bird watching or famously known as birding is a dominant sector of wildlife tourism that involves recreational activity and citizen science.

Citizen science in bird watching has been a common approach. In citizen science program, citizens are trained to identify and collect the attributes of bird species within their neighbourhoods. Several ways can be carried out to detect birds, either visually or by listening to the sound of the birds. Most birdwatchers use visual enhancement devices, such as binoculars and telescopes, in their birding activities. Malaysia is among the most famous countries in Asia for birders. Peninsular Malaysia, and the province of Sabah in East Malaysia, have been recognised and frequently visited by international bird tour groups and also by numerous self-dependent birdwatchers annually. According to Andrew Sebastian (2018), Malaysia has become the habitat of 796 bird species, wherein 64 of them are classified as endemics and not discovered in other places on the planet.

Urbanisation has been considered as a major land-use and landcover (LULC) change with numerous unavoidable consequences to the biodiversity, where several animal species can be positively or negatively influenced by the invasion of 
human communities (Guette et al., 2017). City development changes the landscape and affects the natural ecologies. Local species are traded by new species that can adapt to the urban condition (urban exploiters) (Dallimer et al., 2015). The growing species assimilates with urbanisation over time (Liang et al., 2019). Urban bird communities embrace the changes in living space (Leveau, 2018) and forage human-derived food (Støstad et al., 2017).

Urban landscapes are composed of human-made features, such as concreate structures (buildings, roads), open spaces, patches of green vegetation, and water bodies. In urban regions, bird species is both identified in neighbourhood surroundings features (tree and bush spread, density of houses, and other structures) and in the city (Aronson et al., 2014). The response of bird species to these urban habitats mainly depends on their ability to deal with human-induced disturbances and to exploit the existing resources (Lowry et al., 2013); wherein several native species (urban avoiders) may face extinction, while others increase in abundance and adapt with the new resources that cities offer (urban exploiters).

The question is 'how do the bird communities react to the rapid changes of urban city development?' A study by Puan et al., (2019) investigated the impacts of green area, water and roadside reserve on the abundance of urban birds in Kuala Lumpur metropolitan city. The question that arises is 'how do urban birds respond to LULC changes due to sub-urbanisation in southern Peninsular Malaysia, particularly Johor Bahru city?'

\section{METHODOLOGY}

This section describe the study area, sampling data and the methods that involved in data analysis.

\subsection{Study area and Sampling Data}

Johor Bahru $(\mathrm{JB})$ is a city situated at the southern part of peninsular. It is the second biggest metropolitan territory in Malaysia after Kuala Lumpur (KL). JB metropolitan zone is an industrial and business hotspot of the South Johor Economic Region (SJER), boasting the parts of an extensive variety of significant business and modern brands. The main focus of land use in Johor Bahru city area is primarily for streets which is at $45.35 \%$ and business purposes $36.86 \%$. Just a moderately small percentage of 0.10 to 0.12 is assigned for residential purposes and industrial use (Yuan, 2011). Table 1 shows a list of 21 locations that involved in this study with the total number of bird observations for each location.

Table 1 Birds count based on locations

\begin{tabular}{|c|c|}
\hline Locations & Birds Count \\
\hline Taman Maju Jaya & 2 \\
\hline Taman Istana & 5 \\
\hline Legoland Nusajaya & 16 \\
\hline Johor Causeway & 20 \\
\hline Taman Nora & 20 \\
\hline Kampung Bakar Batu & 36 \\
\hline
\end{tabular}

\begin{tabular}{|c|c|}
\hline Taman Tampoi Utama & 43 \\
\hline Sungai Tebrau & 50 \\
\hline Taman Damansara Aliff & 50 \\
\hline Kawasan Perindustrian Tampoi & 53 \\
\hline Taman Laguna & 53 \\
\hline Taman Dato Onn & 57 \\
\hline Taman Mutiara & 65 \\
\hline Danga Bay & 80 \\
\hline Medini Nusajaya & 85 \\
\hline Kempas Denai & 87 \\
\hline Kampung Dato Sulaiman Menteri & 122 \\
\hline Kampung Sungai Melayu & 157 \\
\hline Taman Sentosa & 178 \\
\hline Kampung Pok & 202 \\
\hline Bukit Chagar & 277 \\
\hline
\end{tabular}

A phone call interview with Mr Vincent Chau, the Vice President of Malaysian Nature Society (MNS) and DOE Registered specialist Consultant in Ecology, Fauna and Flora, was conducted on 9th April 2019 to retrieve more information regarding urban birds. Based on this interview, the three main components that can attract birds are food, shelter, and security. He stated that although birds are always related to forest area, most urban birds prefer to live in urban area than forest area, primarily because urban birds feed on food waste or trash discarded by human. They are commonly found near road side area, where trash discarded by road users is commonly found. Urban birds are also attracted to golf course area as many trees are found there, thus creating a small artificial forest for the urban birds. Nonetheless, the development of golf course area does not attract other bird species, thus the deteriorating forest birds in that area. Factors that are commonly investigated include the influence of LULC changes, temperature and noise level.

\subsection{Data normalization}

By using the Shapiro-Wilk test of Normality in the IBM SPSS Statistics software, it demonstrated that the initial distance for each explanatory variable to the bird's location were nonnormally distributed. Moreover, some of the variables showed a few outliers. In OLS regression, normally distributed data is preferred, or the output analysis cannot be trusted. In order to ensure that all the data are normalized, Box-Cox transformation was applied to all explanatory variable by using Minitab statistic software. Box-Cox transformation represent a group of power transformation that joins and stretches out the traditional option to identify the ideal normalizing transformation for every factor. Each variable was tested using box-cox transformation to identify the most suitable transformation. Hence, transformation of non-normal distribution data were done on all explanatory variable using either square root (sqrt) or natural $\log (\ln )$. Outliers were also identified through box-plot graph and have been removed from the dataset. 
The International Archives of the Photogrammetry, Remote Sensing and Spatial Information Sciences, Volume XLII-4/W16, 2019 6th International Conference on Geomatics and Geospatial Technology (GGT 2019), 1-3 October 2019, Kuala Lumpur, Malaysia

\subsection{Data processing}

The data were processed to generate new attribute by measuring the distance of bird location to each tested variable. The Near tool in ArcMap software was used to measure the distance between input features. Near tool can calculate distance and additional proximity information between the input features and the closest feature in another layer or feature class. The distance calculation is dependent on the geometry type and coordinate system.

Proximity analysis was carried out using Near tool. The distance from each bird point feature to each explanatory variable ( i.e. distance to forest, distance to commercial, distance to road, distance to residential and distance to recreational and open space) were measured and the output was displayed in the birding data attribute table. It provides a summary of the minimum and maximum value for each explanatory variable.

\subsection{Correlation Analysis}

Bivariate correlation analysis is used to determine the empirical relationship between two variables. A correlation expresses the strength of linkage or co-occurrence between to variables in a single value between -1 and +1 . This value that measures the strength of linkage is called correlation coefficient, which is represented typically as the letter $r$. A positive $r$ value expresses a positive relationship between the two variables while a negative $r$ value indicates a negative relationship. A correlation coefficient of zero indicates no relationship between the variables at all. Using SPSS software, bivariate correlation analysis between each independent variable was conducted to understand the relationship between each factor.

Collinearity or multicollinearity causes redundant information, which means that what a regressor explains about the response is overlapped by what another regressor or a set of other regressors explain (Yoo et. al., 2014). Hair et al. (1998) noted that as multicollinearity increases, it is more difficult to ascertain the effect of any single variable produce biased estimates of coefficients for regressors because the variables have more interrelationships. Based on the result, the variables of distance to residential and distance to commercial area for year 2016 and the variable distance to commercial area for year 2018 were removed in order to reduce multicollinearity.

\subsection{Ordinary Least Square (OLS) Regression}

Ordinary Least Square (OLS) is another technique utilized in making prediction and estimation. In geostatistics, OLS or linear least squares is a technique for assessing the unknown parameters in a linear regression model (ESRI, 2016b). The OLS regression model was used to analyse the relationship between the number of bird (frequency) and the explanatory variables which were distance to forest, distance to commercial, distance to road, distance to residential and distance to recreational and open space. All factors were analysed with the dependent variable to identify which variable was the most dominant factors to influence the occurrence of bird. OLS evaluates the global relationship between dependent and independent variables. Table 2 list out the dependent and independent variables that were analysed in this study.
Table 2 A List of dependent and independent variables used in the OLS

\begin{tabular}{|l|l|l|}
\hline \multirow{2}{*}{$\begin{array}{l}\text { Type of } \\
\text { variables }\end{array}$} & \multicolumn{2}{|c|}{ Parameters } \\
\cline { 2 - 3 } Dependent & $\begin{array}{l}|c| \\
\text { Frequency of birds } \\
\text { occurrence }\end{array}$ & $\begin{array}{l}\text { Frequency of birds } \\
\text { occurrence }\end{array}$ \\
\hline $\begin{array}{l}\text { Explanatory } \\
\text { (Independent } \\
\text { variable) }\end{array}$ & $\begin{array}{l}\text { 1. Distance to Forest } \\
\text { 2. Distance to Road }\end{array}$ & $\begin{array}{l}\text { 3. Distance to Distance to road } \\
\text { Recreational and } \\
\text { open space }\end{array}$ \\
$\begin{array}{l}\text { 2. Distance to } \\
\text { Recreational and } \\
\text { open space }\end{array}$ \\
\hline
\end{tabular}

The result of OLS regression tool gives adjusted $\mathrm{R}^{2}$, VIF and coefficient values to demonstrate the performance of the model that comprises of the tested dependent and independent variable. Multiple $\mathrm{R}^{2}$ and adjusted $\mathrm{R}^{2}$ values evaluate the model's performance. As indicated by ESRI (2016a), adjusted $\mathrm{R}^{2}$ value is constantly lower than multiple $\mathrm{R}^{2}$ as it reflects model complexity (number of variable). The adjusted $\mathrm{R}^{2}$ is more precise than multiple $\mathrm{R}^{2}$ at estimating performance since it relates legitimately to the data. The potential range of values is within 0.0 to 1.0. While the variance inflation factor (VIF) measures redundancy among variables, ESRI (2016a) expressed that variables with VIF value bigger than 7.5 need to be eliminated from the model.

The overall model statistical significance was estimated using joint-F-statistic and joint Wald statistic value. The joint-Fstatistic is only acceptable when the Koenker (BP) statistics is not statistically significant (ESRI, 2016). The Koenker (BP) statistic distinguishes whether independent variable in the model have a consistent relationship to the dependent variable both in data and spatial space (ESRI, 2016b). In the event that the model is consistent in spatial space, the spatial process carries on the equivalent behaviours wherever in the study area. ESRI (2016a) expressed that probability (p-values) appears if the regression model is statistically significance and if hypothesis/common sense support a strong relationship with the dependent variable. Independent variable must be linear and not redundant to other independent variable in the model. In a statistically significant model, the p-value must be smaller than 0.05 . A p-estimation of higher than 0.05 , implies the model is not statistically significant and that the model relationship is not consistent. In the event that the model is consistent in data space, the relationship variation between the predicted value and each explanatory variable does not change.

\subsection{Moran's I Spatial Autocorrelation}

In order to understand the data distribution gained from the sources, Moran's I spatial autocorrelation was performed on each explanatory variable. Moran's tool identify if the spatial pattern is either disperse, random or clustered. For the purpose of meeting the prerequisite to carry out OLS regression, data distribution need to be in random and the residual is not statistically significant autocorrelated.

The Spatial Autocorrelation tool provide five values: the Moran's I Index, Expected Index, Variance, z-score, and pvalue. These values can be retrieved from a graphical summary of results in HTML document under Results window in ArcMap. At the point when the z-score or p-value shows statistical significance, a positive Moran's I value suggests 
tendency toward clustering while a negative Moran's I value indicate tendency toward dispersion (ESRI, 2016c).

Morans' I also calculate z-score and p-value to show whether the null hypothesis can be rejected or not. For this study, the null hypothesis expresses that feature values are randomly distributed over the study area. Spatial autocorrelation was performed by running Spatial Autocorrelation (Moran's I) tool under spatial statistic tool in ArcMap to analyze the spatial pattern whether they are spatially random, clustered or dispersed. Statistically significant clustering of high and/or low residuals indicates a key variable is missing from the model (misspecification). The spatial autocorrelation OLS results cannot be trusted when the model is mis specified. The spatial autocorrelation results for year 2016 and 2018 were both spatially random model.

\subsection{Kernel Density}

This study utilized a Kernel density tool to map the hotspot of bird population. The Kernel Density tool computes the density of features in an area around those features (ESRI, 2016a). It can be used to measure the density of both point and line features. Kernel density uses a filtering window to identify the neighbouring object and represent the value of an area; that window moves over the study area until it calculates the values all location. It weighs nearby features more than far ones as per a Kernel function. Density surfaces show where the point or line features are concentrated.

\section{RESULTS AND DISCUSSIONS}

\subsection{Data Distribution}

The aim of this study is to analyse the factors that influence bird's population in Johor Bahru area. A total of 614 birds on year 2016 and 999 birds on year 2018 from five different species were sampled in this study. Figure 1 shows the total number of birds studied based on their species for year 2016 and 2018. The highest number of birds spotted in year 2016 is Javan Myna with 324 birds, while in year 2018, the most bird spotted is House Crow which is 498 birds. The total number of bird count for all species were increasing except for Javan Myna which decreases by $52.78 \%$ where it is mainly located at Danga Bay, Bukit Chagar and Taman Tampoi Utama, which are mostly residential area.

\section{Birds Population by Species}

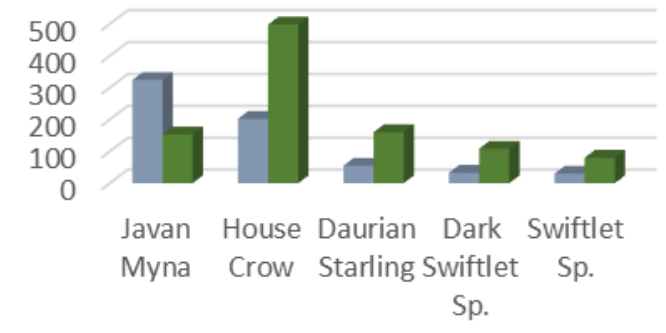

—2016 2018

Figure 1 Number of birds spotted in year 2016 and 2018
Figure 2 and Figure 3 shows the distribution of urban birds' population for year 2016 and 2018, respectively by using ArcMap. Based on Figure 2 and 3 the number of observation points increased from 21 observation points in year 2016 to 41 observation points in year 2018. The locations of observation are focused on Johor Bahru, Pulai, Tebrau and Iskandar Puteri. Each bird species is represented using different colour. In the following figures, yellow, red, blue, purple and green for Daurian Starling, House Crow, Javan Myna, Dark Swiftlet Sp. and Swiftlet Sp. respectively.

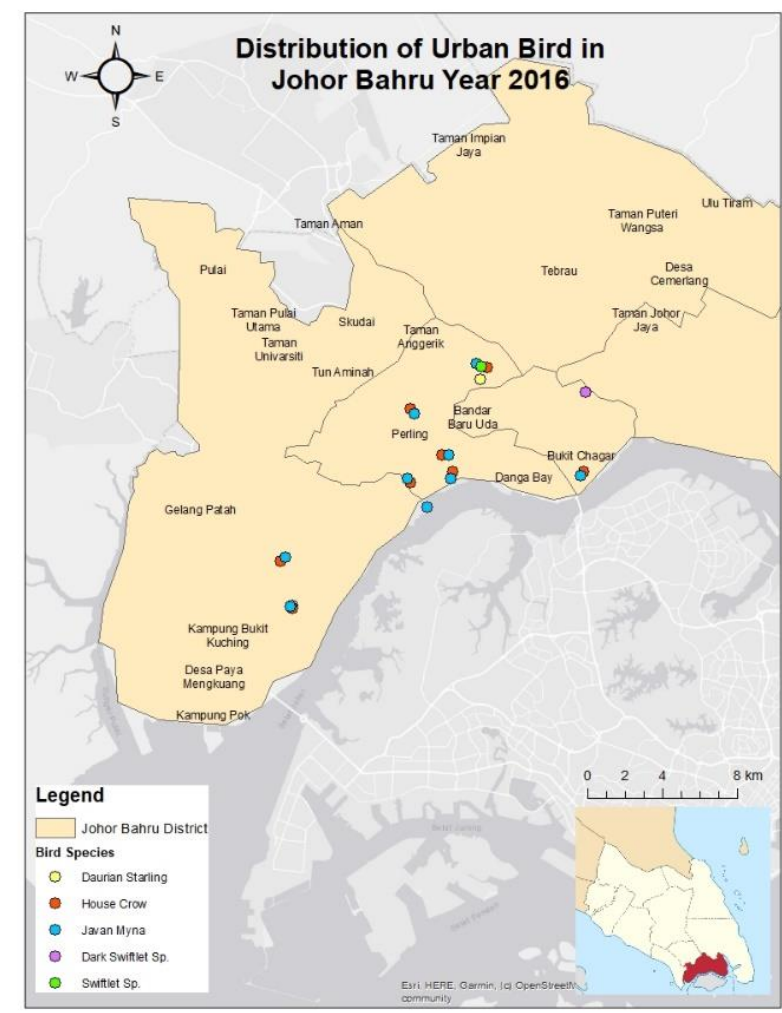

Figure 2 Distribution of urban bird by species in year 2016 


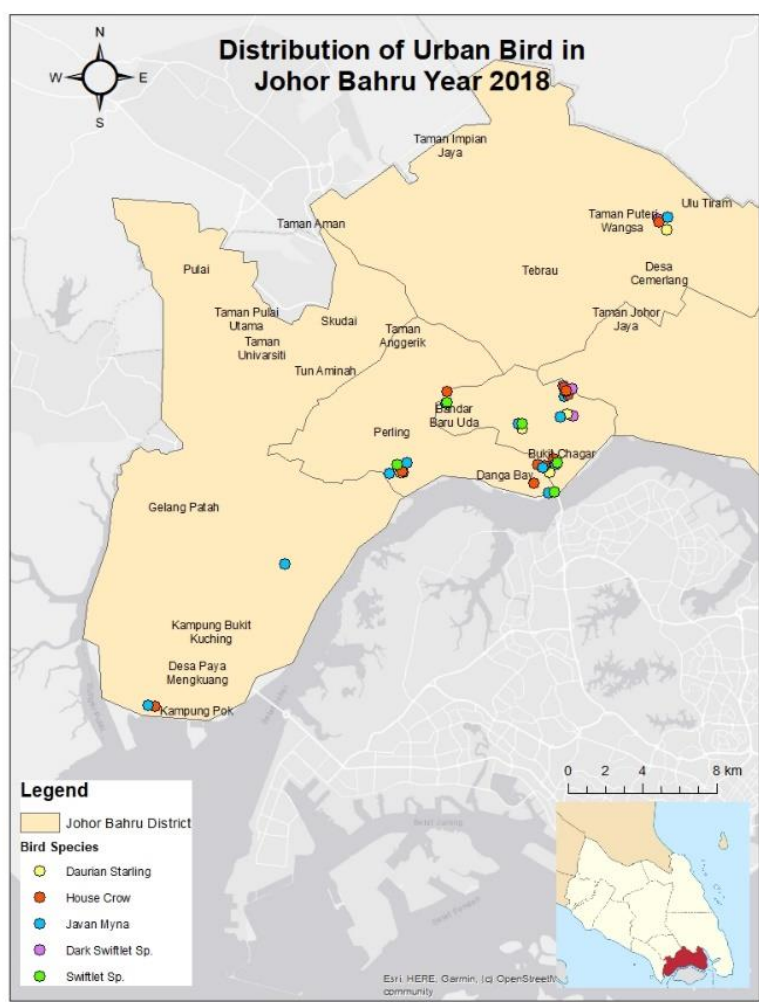

Figure 3 Distribution of urban bird by species in year 2018

\subsection{The Influence of Land Use Land Cover Changes to}

\section{Bird Occurrence}

Bivariate correlation analysis was carried out between each independent variable (i.e. distance to forest, distance to commercial, distance to road, distance to residential and distance to recreational and open space) against the dependent variable (frequency of urban bird occurrence) for both year 2016 and 2018. The species of birds that grouped as urban bird in this study were Daurian Starling, House Crow, Javan Myna, Dark Swiftlet Sp. and Swiftlet Sp. The occurrence of individual bird species as stated in Figure 1 has been regressed, but no significant variable has been identified. Therefore, the models derived in this study used a group of urban bird species as the dependent variable.

Therefore, three independent variables for year 2016 and four independent variables for year 2018 were investigated their relationships with the number of bird's occurrence in this study. However, in order to obtain the best result, a few combinations of OLS regression models were tested. Model that have the best adjusted $\mathrm{R}^{2}$ is considered as the best model that fit with this study. Due to this, after combination, the variable distances to forest $\left(R^{2}=-0.024329\right)$ and distance to residential area $\left(R^{2}=\right.$ 0.022240 ) were removed from OLS analysis year 2018. Only three variables (i.e. distance to forest, distance to road and distance to recreational and open space) were used for the OLS analysis for year 2016 .

From OLS regression for year 2016, this model shows the result of multiple $R^{2}=0.43$, while adjusted $R^{2}=0.33$. For year 2018 , this model shows the result of multiple $R^{2}=0.15$, while adjusted $\mathrm{R}^{2}=0.11$. Thus, this model can explain approximately $33 \%$ of the variation in the dependent variable for year 2016 and $11 \%$ for the year 2018. According to Alshibly (2018) the higher the $\mathrm{R}^{2}$, the better the model fits the data. In particular, value of Adjusted $R^{2}$ reflects the goodness of fit of the model to the population considering the sample size and the number of predictors used.

Each explanatory variable was assessed. The result shows the summary of the coefficient, probability (p-value) and VIF values to show the relationship between dependent and independent variables by using OLS model for year 2016 and 2018. In the year 2016, distance to forest and distance to recreational and open space are positively associated with the number of bird occurrence. In contrast, distance to road are negatively associated with number of bird occurrence. This means that the relationship is inversely proportional to the dependent variable. In other words, shorter distance to road features will lead to a higher number of bird. In the year 2018, distance to road and distance to recreational and open space is inversely proportional to the number of bird occurrence. Based on the OLS model for year 2016 and 2018, the VIF of all explanatory variables (i.e. distance to forest, distance to road and distance to recreational and open space) are less than 7.5. This indicates that the explanatory variables are not redundant with one another.

This study discovered that in year 2016, the factors of distance to forest and distance to road significantly influenced the presence of urban birds. This is in line with the study carried out by Puan et al., (2019), which determined the role of roadside in influencing the abundance of specific birds, particularly Myna and Starlings species, which can adapt rather well in building nests within concrete flyover walls. The study reported that increase in distance to forest promoted the abundance of urban birds, wherein such bird species lives in open cosmopolitan area and does not belong to the forest habitat.

As for year 2018, distance to recreational and open space emerged as the some dominant factor that influenced urban bird occurrence in Johor Bahru city. According to Chau (2019), places that can provide food, shelter or security can greatly attract birds. That study stated that roadside area usually has food waste discarded by road users, thus attracting birds. Urban birds are not attracted to forest area as that is not their habitat area. Urban birds prefer area with more human settlements where they can scout for abundant food at garbage dumps and along roadside. This is supported by the results of OLS model for year 2016, where the OLS outcomes showed that distance to road and distance to forest area significantly depended on urban bird occurrence.

Based on the findings reported by Idilfitri et al., (2014), native plant species offers a great deal of benefits to bird community in urban areas, especially in enhancing the bird population. Native plant species is the most competent to provide all-year-round food resource and better shelter. This is proven in the OLS model for year 2016, where the OLS outputs signified that distance to recreational and open space significantly influenced bird occurrence. 


\section{3}

\section{The Effect of Sub-Urbanization to Bird}

\section{Occurrence}

Kernel density tool under spatial analyst tool in ArcMap was used to study the distribution density of bird's population for both year 2016 and 2018 in Johor Bahru area. Figure 4 and 5, shows the density of bird's population distribution by using the gradient colour (green to red) for year 2016 and 2018 respectively. Red colour cell represents area where there are more records around them compared to green cells. The higher the value of kernel density, the higher the concentration of bird population.

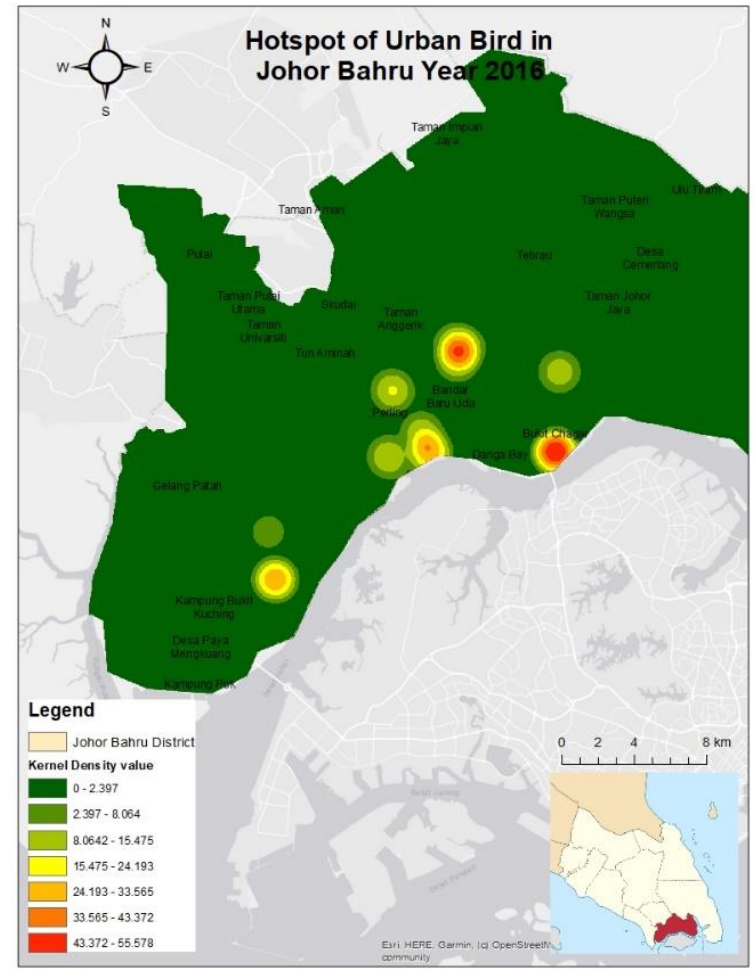

Figure 4 Urban Bird distribution for year 2016

From Figure 4 and 5, the hotspots for bird population in the year 2016 occur in Danga Bay and Kempas Denai, while in the year 2018, the hotspots occur in Kampung Pok, Bukit Chagar, Taman Sentosa and Kampung Dato Sulaiman Menteri. The changes in hotspot bird area may due to the land use land cover changes between the year 2016 and 2018. For example,in Kampung Pok area, it has been identified as a hotspot area for year 2018 but not in 2016 due to the increase of recreational and open space area and decrease in forest area.

This study identified that the hotspots of urban bird area in Johor Bahru were changes from the year 2016 to 2018. Table 3 shows the difference in the land cover area between year 2016 and 2018. Based on Table 3, there is a significant increment in the total area of recreational and open space in Johor Bahru. Based on the result from the OLS model for year 2018, it stated that distance to recreational and open space is the significant factor that influence to the occurrence of urban birds in the year 2018.

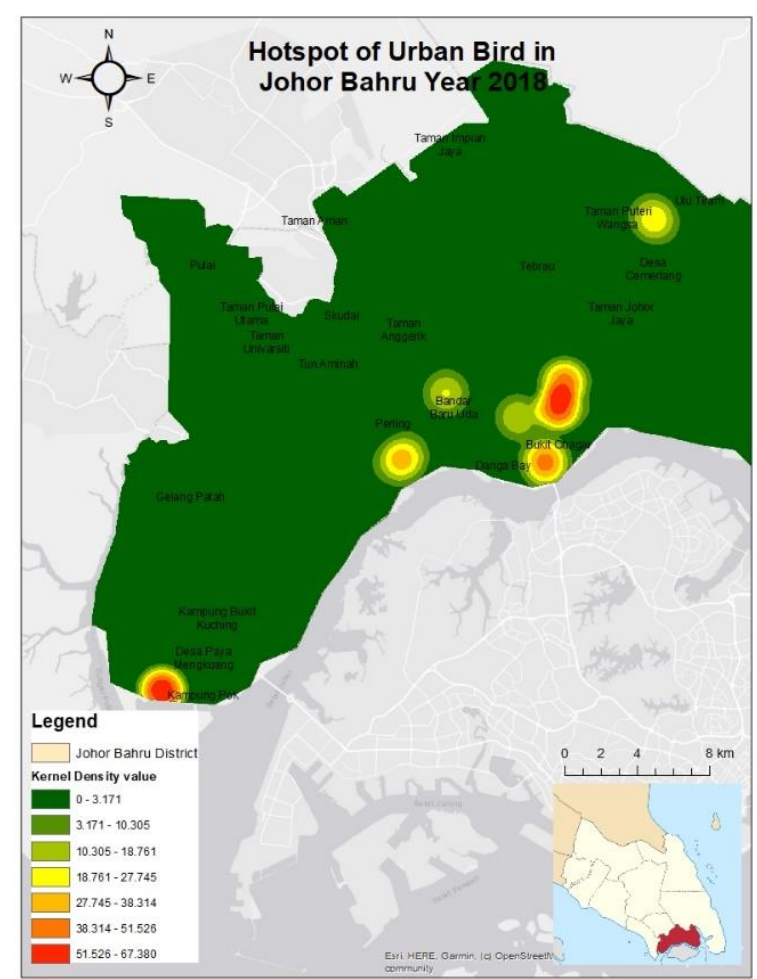

Figure 5 Urban Bird distribution for year 2018

The increase in the number of birds spotted in Johor Bahru may due to the increase of recreational and open space area in Johor Bahru. Based on the result of OLS for year 2016, distance to forest area is significant. However, the result of OLS for year 2018 shows the distance to forest area less influence to the urban bird occurrence. This result may be due to the size of forest area that was reduced from the year 2016 to 2018 by $32.83 \%$.

Table 3 Landcover area for year 2016 and 2018 for Johor Bahru District

\begin{tabular}{|c|c|c|}
\hline \multirow{2}{*}{ Landcover types } & \multicolumn{2}{|c|}{ Area (hectare) } \\
\cline { 2 - 3 } & $\mathbf{2 0 1 6}$ & $\mathbf{2 0 1 8}$ \\
\hline Forest & 6434.026547 & 4321.960592 \\
\hline $\begin{array}{c}\text { Recreational and Open } \\
\text { Space }\end{array}$ & 3283.046558 & 3836.055372 \\
\hline
\end{tabular}

Figure 6 shows the distribution of birds overlaid with land cover map in Kampung Pok for year 2016 and 2018. The land cover of Kampung Pok area is changing from the year 2016 to year 2018 as seen in Figure 6. The forest area in year 2016 was no longer present in the year 2018. Increment in the size of recreational and open space area was noted in year 2018. This change may attract urban birds into Kampung Pok area, as this study found that location is a hotspot for occurrence of urban birds in Johor Baharu. However, no urban bird observation data was found in Kampung Pok in year 2016, except for other bird species, such as Brahminy Kite, a mangrove forest bird was spotted, hence comparison of increment and decrement of urban birds between years cannot be made.

The recreational and open space area is a prominent factor that attracts more urban birds based on the OLS model for year 
2018. Changes in the total area of LULC between year 2016 and 2018 had been identified in terms of decrease in the total area of forest and road, while a significant increase in the total area of recreational and open space. Such increment offers basis evidence to the increment of the total number of urban birds spotted in Johor Bahru area as significant increase in the total area of recreational and open space denotes a huge decrease in the total area of forest.
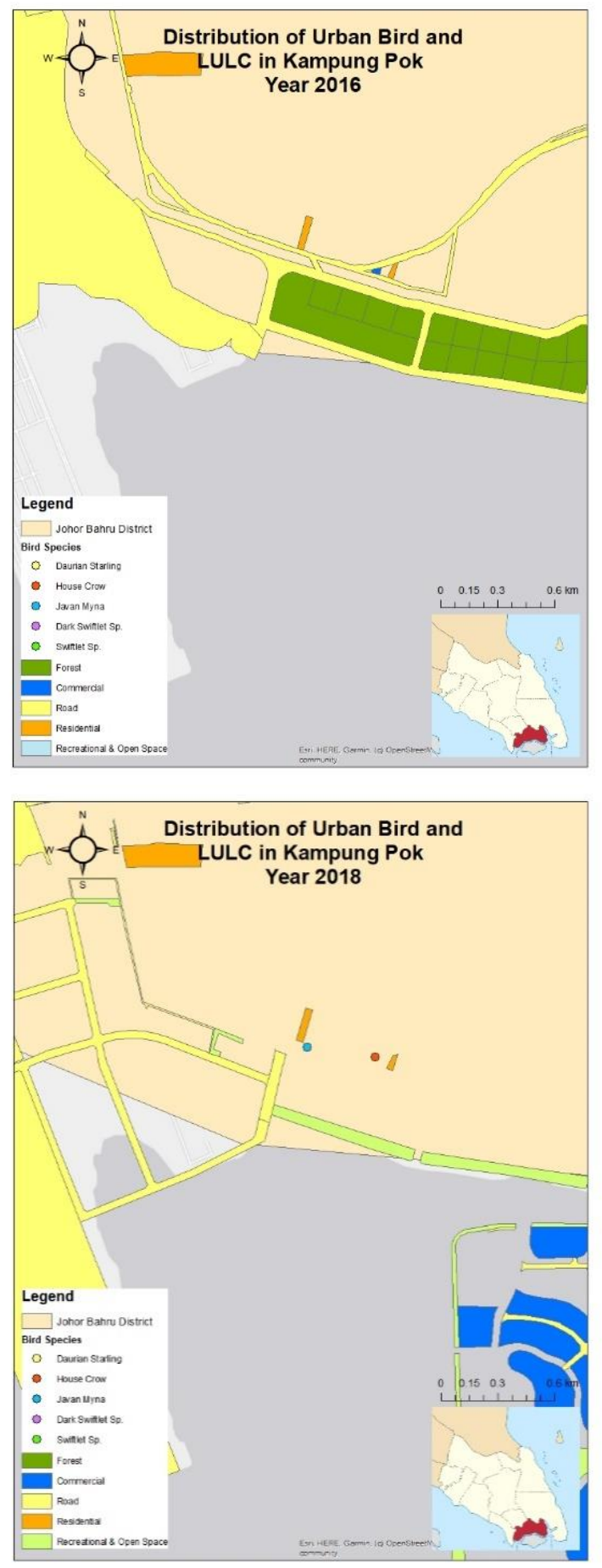

Figure 6 Bird distribution over land cover map in Kampung Pok for year 2016 and 2018

\section{CONCLUSION}

This study presents the significant factors that influenced the occurrence of birds, including distance to road and distance to forest for year 2016, while distance to recreational and open space for year 2018. The relationship between community of birds and distance to road, as well as distance to recreational and open space, is negatively associated. This means; the shorter the distance to road and recreational and open space, more birds are spotted. Urban birds are attracted to places where there are more human settlements, as the abundance of food waste is a rich resource for survival. Additionally, not all urban bird species are distracted by noisy road. Recreational and open space area that houses native plant species attracts birds into the area due to availability of food resources and better shelter for the birds throughout the year.

The correlation between birds' population and distance to forest area is positively associated. This means; more birds are spotted further from forest area. Urban birds are not attracted to forest area. Change in LULC from forest to recreational and open space may extinct the forest bird habitat, but attracts larger open birds habitat, especially for urban exploiters to adapt with the changes. The increase in the number of urban birds spotted in Johor Bahru is attributable to the increase in recreational and open space area, as well as decrease in the size of forest area in Johor Bahru.

Several limitations have been noted in this study. Due to the scope of data that relied on eBird crowd sourced observations, the findings might not be generalised to the whole area of Johor Bahru city. The crowd source data applied in this study may be biased to certain species and favourite locations by the volunteers, as well as incomplete data collection as a result of voluntary activities. This study is significant with contribution to urban landscape planning to promote sustainable development that incorporates habitat of urban birds' biodiversity in a city. The study outcomes may serve as a basis for various parties interested in LULC changes and their impact to urban bird species distribution and abundance.

\section{ACKNOWLEDGEMENTS}

The authors would like to thank eBird for providing the birding dataset and Mrs. Noridah binti Mohamed Noor from the PlanMalaysia for supplying the LULC map. This project was supported by the Universiti Teknologi Malaysia and Ministry of Education Malaysia (GUP grant 17H13).

\section{REFERENCES}

Amanullah, M.M., Sekar, P. and Muthukrishnan, P. (2010). "Prospects and Potential of Poultry Manure". Asian Journal of Plant Sciences, 9: 172-182.

Aronson, M. F., et al. (2014). "A global analysis of the impacts of urbanization on bird and plant diversity reveals key anthropogenic drivers." Proc Biol Sci 281(1780): 20133330.

Alshibly, H. H. (2018). How to justify low R-squared and adjusted R-square values? 
Chau, Vincent. Vice president. Malaysian Nature Society and DOE Registered specialist Consultant in Ecology, Fauna and Flora.

Chua LS, Zukefli SN. (2016). A comprehensive review on edible bird nests and swiftlet farming. Journal of Integrative Medicine, 14(6): 415-428.

Dallimer, M. D., Z. G.; Diaz-Porras, D. F.; Irvine, K. N.; Maltby, L.; Warren, P. H.; Armsworth, P. R. \& Gaston, K. J. (2015). "Historical influences on the current provision of multiple ecosystem services." Global Environmental Change 31: 307-317.

Duncan A.I. Lang, D. B. M. M. (2014). "A National Red List for The Birds Of Malaysia." Journal of Wildlife and Parks, 28: 41-49.

ESRI. (2016a). Interpreting OLS Results. Retrieved 9 June, 2018, from http://desktop.arcgis.com/en/arcmap/10.3/tools/spatial-statisticstoolbox/interpreting-ols-results.html

ESRI. (2016b). How Kernel Density works. Retrieved 9 June 2018 , from http://desktop.arcgis.com/en/arcmap/10.3/tools/spatial-analysttoolbox/how-kernel-density-works.htm

ESRI. (2016c). Spatial Autocorrelation (Global Moran's I). Retrieved $10 \quad$ June, 2018, from http://desktop.arcgis.com/en/arcmap/10.3/tools/spatial-statisticstoolbox/spatial-autocorrelation.htm

Guetté, A., et al. (2017). "Measuring the synanthropy of species and communities to monitor the effects of urbanization on biodiversity." Ecological Indicators 79: 139-154.

Hair Jr., J. F. et al. (1998). Multivariate Data Analysis with Readings. Englewood Cliffs, NJ: Prentice-Hall.

Idilfitri, N. H. N. M. (2012). "Role of Ornamental Vegetation for Birds' Habitats in Urban Parks: Case study FRIM, Malaysia." Social and Behavioral Sciences, 68: 894 - 909.

Kitamura, S. (2015). "Ecosystem services provided by birds: special reference to pollination and seed dispersal by birds." Japanese Journal of Ornithology 2015 Vol.64 No.1 pp.25-37

Leveau, L. M. (2019). "Primary productivity and habitat diversity predict bird species richness and composition along urban-rural gradients of central Argentina." Urban forestry \& urban greening.

Liang, C., et al. (2019). "Taxonomic, phylogenetic and functional homogenization of bird communities due to land use change." Biological Conservation 236: 37-43.

Lowry et al. (2013). "Behavioural responses of wildlife to urban environments” Biol. Rev. (2013), 88, pp. 537-549.
Puan, C. L., et al. (2019). "Influence of landscape matrix on urban bird abundance: evidence from Malaysian citizen science data." Journal of Asia-Pacific Biodiversity.

Sebastian, Andrew (2018). "Andrew Sebastian: On Malaysia Ecotourism \& Ecology".

Støstad, H. N. et al. (2017). "Foraging on human-derived foods by urban bird species" Bird tudy, 64:178-186.

Vrschmalhofer. (2018). “Why Birds Matter”. Centre for Earth and Environmental Science Blog. Available at https://cees.iupui.edu/blog/why-birds-matter (Accessed: 19 August 2019).

Wang, Y., et al. (2019). "Human-perceived temperature changes over South China: Long-term trends and urbanization effects." Atmospheric Research 215: 116-127.

Yoo, W., Mayberry, R., Bae, S., Singh, K., Peter He, Q., \& Lillard, J. W., Jr (2014). A Study of Effects of MultiCollinearity in the Multivariable Analysis. International journal of applied science and technology, 4(5), 9-19.

Yuan, G. S. (2011). "The quality of life in city centre for revitalisation (case study: Johor Bahru city centre). 